\title{
International and European in the Accounting System of Romania
}

\author{
Anca Gabriela TURTUREANU* - \\ Cornelia Elena TUREAC**
}

\section{Introduction}

The Fourth Guideline of the Counsel, coordinates the assembly of the requests imposed to the member states and that are going to adhere concerning the presentation and content of the yearly financial situations and of their reports, the general principles concerning the evaluation of the position and the financial performance of an entity, specific rules of evaluation of the assets and the liabilities and the publishing of the yearly accounts. At the same time, the guideline states the demands concerning the statutory audit of the yearly financial situations by the authorized persons to make audience in this in this purpose, in accordance with the European demands. Rules that are less harsher are established for the small and medium companies, in this way the member states being able to decide that the obligations concerning the drawing-up, the audition and the publishing of the financial situations to be less strict or can except the small companies from the respecting of the demand concerning the audition of the yearly accounts.

The small companies are those which, at the date of the annual balance sheet do not surpass the limits of two of the three criteria (Fourth Council Directive 78/660/EEC, EC, 1978, p. 79):

- total of balance sheet: 3.650 .000 euro;

- the net turnover: 7.300.000 euro;

- number of employees: 50.

The member states are able to decide that the obligations concerning the accounting and the publishing of the yearly financial situations of the

\footnotetext{
Ec. ing. Anca Gabriela Turtureanu - Reader PhD; Scientific Secretary of Faculty of Economics Sciences, "DANUBIUS" University Galati, Galati Boulevard 3, 800654, Galati, Romania; <ankterra@yahoo.com>.

** Ec. Cornelia Elena Tureac - Reader PhD; Scientific Secretary of Faculty of Economics Sciences, "DANUBIUS" University Galati, Galati Boulevard 3, 800654, Galati, Romania; <cornelia_tureac@yahoo.com>.
} 
medium companies to be less strict and harsh. The medium companies are the ones that care do not surpass two of the three criteria (Seventh Council Directive 83/349/EEC, EC, 1983, p. 65):

- total of balance sheet: 14.600 .000 euro;

- the net turnover: 29.200 .000 euro;

- number of employees: 250.

We must mention that these exceptions are not accepted by the Guideline for the companies that are listed at Exchange, no matter the size.

The Fourth Guideline is based on the article 53 of the Treaty of Rome, is considered a compromise of a legislative type of the financial report and the approach based on the concept of a faithful image. This accountancy document offers the possibility of choosing between more accounting alternatives of solving the different problems and also offers to the member states options regarding its application.

The first project of this guideline was published in 1974 and it was influenced by the Law of the German Business Corporations from 1965. Besides the German influence, the guideline also had a powerful Dutch influence. The German influence marks the thematic for the evaluation in accordance with the method of the historic costs and adopting of some specific instructions concerning the presentation of the accounting balance sheet and of the profit and loss account. The Dutch influence is based on the option of choosing the evaluation bases and the brief description of the yearly accounts. In this stage, the guideline had as purpose the obtaining of an image that is extremely sure of the companies. The joining of the Great Britain in the European Union imposes the concept of a faithful image, in such a way that the yearly accounts should satisfy the principles of an accounting system in accordance with the rules and confer a faithful image upon the companies. These ideas have influenced the content of the guideline concerning the presentation rules of the financial situations and of those of evaluation of the described elements in them. The historic cost has become in an official way the main basis of evaluation in the accounting system, the other bases being considered as its derivative. The including of the Anglo-Saxons in the European Union opened the process of normalization on the basis of a subtle process, inspired by influence of the capital markets that direct the accounting and booking mechanisms towards the ones with custom basis, in the disadvantage of the rigid and exhaustive ones. 


\section{The role of the Fourth Guideline in the European process of normalization and conformity}

The accounting harmonization for the Fourth Guideline imposes the principle of a faithful image as a main element of the group of accounting principles, thus considering that the other principles derive and subordinate to it (Fourth Council Directive 78/660/EEC, EC, 1978, p.37).

The introduction in the national legislations of the content of the Fourth Guideline should have been accomplished until July 1980, but no member state accomplished this thing, in the present the content of this document is included in all the legislations of the member states, as well as in the content of the legislations of other states that are not members.

The Fourth Guideline is made up of 61 articles, grouped in 12 sections. The sections of the guideline are the following (Fourth Council Directive 78/660/EEC, EC, 1978, p. 133):

S1: General dispositions;

S2: General dispositions concerning the balance sheet and the loss and profit account;

S3: The balance sheet formats;

S4: Special dispositions concerning certain articles from the balance sheet;

S5: The loss and profit account format;

S6: $\quad$ Special dispositions concerning certain articles from the balance sheet;

S7: Rules of evaluation;

S8: The annexes from the balance sheet;

S9: $\quad$ The content of the yearly report;

S10: Publicity;

S11: The audit;

S12: Final dispositions.

Article 1 states the application sphere of the stipulations of this document, which it applies especially to the share companies, the private limited companies and their equivalents. The guideline authorizes the member states that in certain circumstances they should grant waivers to certain companies from the obligations referring to the publishing, the presentation and control of the accounts, the only acceptable criterion in such waivers being the size of the company. The waivers are admitted if 
the companies accomplish two of the three criteria mentioned by the present guideline.

Article 2 presents the types of yearly accounts: the balance sheet, the loss and profit account and its annex, all these forming a unitary whole. The main objective of the accounting harmonization is also presented in article 2 and consists of the fact that," this requests the conferring of a faithful image of the estate or national wealth, of the financial situation and of the results of a society".

The presentation of the yearly accounts is realized by articles 3-30. Within these articles there are presented the obligatory formats of them.

For the balance sheet there are foreseen two formats: the horizontal one and the vertical one. The horizontal scheme of the accounting balance sheet is composed of 6 headings for assets (A. .. F) and 5 for the balance liability (A ....E). The vertical scheme or list permits the calculus of the net status of the estate or national wealth, being formed of headings from A .... L. In addition to the structures described for the balance sheet, the guideline certifies that the member states can realize waivers, especially for the following items:

a) The presentation of the subscribed capital and of the called and unpaid capital;

b) The promotion expenses;

c) The research- development expenses;

d) Concessions, patents, licenses, brands;

e) Shares or own parts;

f) Settlement accounts of asset and liability;

g) The result of the exercise.

For the loss and profit account there are stipulated 4 schemes: two under vertical form and two under horizontal form. The difference between these two categories is given by the fact that certain schemes classify the expenses depending upon the nature or type, and others upon the function (Barry and Epstein, 2007, p. 77). The guideline does not impose the type of balance sheet or loss and profit account which must be adopted by a company, but oblige that from exercise to another the companies do not change their format.

The guideline also presents the evaluation rules accepted, that are in fact the accounting principles generally accepted, such as the following (Fourth Council Directive 78/660/EEC, EC, 1978, p. 79) (Bunea Garbina, 2005, p. 54): 
a) The principle of the continuity of the activity;

b) The principle of prudence;

c) The principle of the permanence of the methods;

d) The principle of the non- compensation;

e) The principle of the intangibility of the opening balance sheet;

f) The principle of specialization of the exercises;

g) The principle of the historical or original cost;

h) The principle of the separate evaluation of the elements of asset and liability;

i) The principle of the predomination of the economic part upon the juridical one.

The principle of the continuity of the activity presupposes that the company continues in a normal way its activities. In the case that the administrators of the company are aware that there are certain unsafe elements concerning its incapacity of continuing the activity, these things must be specified in the annex.

Depending upon the two states that can be encountered (the continuity or discontinuity of the activity) there are distinguished two consequences concerning the way of drawing up the inventory and implicitly of the financial situations, such as the following (Obert, 2005, p. 92):

a) in case of continuity of the activity, the estate or national wealth elements are evaluated by taking into account the utility value, the market value of the elements that are comprised in the inventory;

b) in case of discontinuity of the activity, the estate or national wealth are evaluated on the bases of the liquidity values, respectively possible to be obtained through the accomplishment of the company's asset.

In function of the way in which this principle affirms itself, it also depends the action mood of the other principles, that in function of the continuity or the discontinuity of the company they will change their action mood, or the most important principle, the prudence principle.

In this way the legislations of some European countries have requested to the accounts commissaries to rigorously examine the relevant aspects that could lead to the discontinuity state,

The National Company of the Accounts Commissaries from France has elaborated a list of the appreciation criteria of the discontinuity state: (International Standards of Financial Reporting, IASB, 2007, p.72) 
- criteria concerning the exploitation activity:

- The insufficiency of the self- financing capacity;

- The insufficiency of the stocks for the insurance of the continuity of the production or sales;

- The deterioration of the demand on the dominant market segments;

- The loss of the utility of the patents and licences.

- criteria concerning the financial activity:

- Insufficient floating capital/ working capital;

- Negative treasury;

- Negative national wealth situation;

- criteria concerning the social aspects:

- Serious and repeated social conflicts:

- The mass departing of the staff as a result of a non-simulative working climate and that lacks perspectives.

In the case that these discontinuity conditions are evident, passes to the evaluation and the presentation of the financial situations based on the actual reality, such as: the total liquidation of the company, its selling, and the giving up of a part of the asset by selling it.

The principle of prudence must be applied mainly in the following situations:

- In the case of the benefits realized at the date of the balance sheet;

- In the case of the predictable risks and of the eventual losses that have their origin in the course of the exercise or during the previous one, even if these risks or losses are not known but only between the date of the balance sheet and the date of the authorization for the deposing;

- In the case of the depreciations, no matter the nature of the result of the exercise.

The General French Account Plan defines the prudency as being the reasonable appreciation of the facts, in such a way that the transfer risk should be avoided in the future of the present uncertainties capable of encumber the national wealth and the result of the company (Barry and Epstein, 2007, p. 98). This implies the accounting of all the probable losses and expenses and the non- accounting of the possible gains and profits. 
Turtureanu, A.G. - Tureac, C.E.: International and European in the Accounting System of Romania.

The application in practice of this principle is connected in a direct way to the evaluation of the elements of the financial situations in the four main moments, such as the following (Obert, 2005, p. 73):

a) at the date of entering in the national wealth;

b) at the date of the stocktaking;

c) at the date of drawing up the balance sheet;

d) at the date of leaving the national wealth.

At the moment of the entry in the national wealth the elements of the financial situations are evaluated as follows (International Standards of Financial Reporting, 2007, p.82):

The goods entered in the national wealth with valuable consideration are evaluated at the acquisition cost composed of: the purchase price, the irrecoverable fiscal taxes and the extra expenses concerning the transport and the installation of the respective elements;

- The goods entered in the national wealth through production are evaluated at the working cost composed of: the direct working costs and the indirect expenses allotted upon the cost of the respective goods taking into account some reasonable criteria, being tightly connected to the production of the goods;

- The goods entered in the national wealth with free title are evaluated at the utility value.

At the moment of stocktaking the elements of the financial situations are evaluated through the utility value by comparison with the most adequate techniques of each element, such as: the market price, the specific and general indexes of the prices, etc.

At the moment of drawing up the balance sheet, the evaluation of these elements implies the application of the prudence principle through which it is compared the book value of each element with the stocktaking value, being applied the following procedure:

- In the case of assets the capital gain or surplus value (the stocktaking value being higher than the book value) is not booked, while the minus is booked under the form of a depreciation provision if this is under a reversible form or of an exceptional depreciations if this takes an irreversible form;

- In the case of the liabilities the capital gain or surplus value is usually booked under the form of provisions for risks and expenses, but the minus of value that have a reversible value are not booked. The ones that have a definitive character are booked 
under the form of some benefits for the society, for example the annulment with definitive character of a debt.

At the moment of leaving the national wealth the elements of the financial situations are usually evaluated at the entry value (the historical value), but one cannot ignore the values regarding the depreciations and provisions concerning the elements leaving the national wealth between the moment of entry and the moment of leaving. Also, we must also take into account the evaluation methods specific to each element type, for example in the case of the inventories or stocks there are used more methods, such as: FIFO, LIFO, CMP, etc. (Collection of guides, 2004, p. 125).

The principle of the permanence of the methods (Chebac, 2009, p. 223) - presupposes that all the evaluation methods should not be modified from one exercise to another. Practically, in reality this principle aims at applying the same accounting politics concerning the evaluation, the bookkeeping entry and the presentation of the elements of the financial situations in order to ensure the comparability of the information in time and space. The modification of these rules and norms (accounting politics) is possible only if this fact is requested by law, by an accounting or bookkeeping standard or if it has as a result the obtaining of certain financial information that are more relevant and trustworthy. (Feleaga and Malciu, 2005, p. 78) For example, if a stock is evaluated in exercise $\mathrm{N}$ through the method of the weighted average cost (WAC), and in exercise $\mathrm{N}+1$ through the FIFO method, the comparability of the information from an exercise to another becomes more difficult to accomplish, although the change of the method was presented in the annex. The action of this principle dose not envisage only the evaluation way of the elements of the financial situations, but also the way of registering of some operations and their reflexion in the financial situations. For example, if at the end of a financial exercise it is noticed the insolvability of a client for whom it is constituted an adjustment for the depreciation, its accounting way influences the presentation of the information in the financial situations.

In the case that this adjustment is of the nature of the depreciation of the claim, the value of the respective claim shall be diminished correspondingly in the accounting balance sheet that is going to affect the net situation of the company. If the provision is registered as being in the category of the ones for risks and expenses, then the value of the claims in the balance sheet is not affected, neither the one of the net situation (Feleaga and Malciu, 2004, p. 110). 
The application of this principle must not be generalized, because it will lead to the slowing of the progress of the accounting process, the main situations with the help of which it is imposed the change of the accounting politics are the following:

a) the change of the economic and fiscal legislation;

b) the obtaining of some more relevant and trustworthy information;

c) the reorganization of the company's activity;

d) the change of the economic and commercial strategies.

In all the situations of the action of this accounting principle, the central element must constitute the obtaining of a faithful image of the national wealth, of the results and financial position.

As reported to the accounting practice there were encountered situations by which the application of this principle had some hidden interests, the most common one being the modeling of the result, depending upon the utilized evaluation method.

The principle of the non- compensation - forbids the effectuation of adjustments/ equalizations between the items of assets and liabilities and expenses-incomes. The action of this principle must not be generalized, but even the international norms mention and stipulate some exceptions.

The central idea of this principle consists of the fact that each transaction realized by the company has at its basis a contract, and the obligation of the accounting system is to deliver as accurate as possible the result of each transaction, being forbidden the compensation of the losses of a contract with the benefits registered in the account of others. As a reaction to this rule, the Order of the Auditors/ Qualified Accountants from France recommends the following operations in connection to these, such as: their regrouping or their division into shares, if certain conditions are accomplished.

Regrouping the contracts can be accomplished if:

- The contracts were signed and concluded in identical or similar circumstances;

- The duration of these regrouped contracts is short;

- This operation must take place before the unfolding of the specific operations of each contract;

- Between these it must exists a direct economic connection.

- The division into shares of a contract can be accomplished if:

- Each division into shares of the contract makes the object of a distinct offer in the relationship with the respective client; 
- The client should have the possibility to conclude a subcontract for each division into shares of the main contract.

The principle of the intangibility of the opening balance sheet implies that the opening balance sheet of an exercise should not correspond to the one of the closing of the previous exercise.

From the point of view of the presented values for each element from the financial situations, these must be similar, but from the point of view of the determination of the accounting reality at a certain time and moment, this principle must not be generalized, its action being affected by some exceptions, especially concerning the changing of the accounting politics and the correction of the fundamental errors, in such a way that the initial situation of the present or actual exercise should not be affected. This principle brings into discussion another principle that is the one of the uniqueness of the balance sheet. The unique character of the balance sheet is considered by some accounting specialists or experts as a compromise between the producers and users of accounting information, being a bridge of connection between objectivism and subjectivism concerning the accounting reflection, between the multitudes of possible images that could reflect this financial situation.

Regarding this aspect Bernard Colasse remarked: "The uniqueness of the balance sheet implies a complex process of exchange and negotiations envisaging a unique synthesis; the good enfolding of this process, taking into consideration the complexity of the problems to be treated and of the diversity points of view, cannot be but accidental and precarious" (Bernard, 2000, p. 83).

The giving up at this principle opens the way to the accomplishment of multiple financial situations, being affirmed the idea of the confusion of the orientations on the basis of the financial information and implicitly it is going to be affected the way of taking economic decisions by the users of these sets of financial situations. As any new element, it encounters for and against opinions, and in this way some authors affirm that the financial information are constructions where there are combined objective and subjective elements, not necessary from the wish of the social influences (normalisations, producers and users), but from the fact that the company represents a complex through which there are combined and welded objective and subjective aspects, and the financial information have the obligation of presenting them according to the reality. 
The principle of specialization (independence) of the exercises presupposes the registering of the expenses and incomes to be accomplished without taking into account the date of payment, respectively the date of the incoming. The application of this accounting principle is conditioned by the following aspects:

- The functioning of the accounting system must have at its basis the concept of liability accounting;

- The utilization of the settlement accounts through which the transactions of each financial exercise are separated;

- The determination of the value depreciation, reversible and irreversible ones for each element of the financial situations;

- The presentation of supplementary information in the annex concerning certain transactions unfolded in the present exercise that are going to affect the result of the future exercises;

- The registering in the account of the present exercise of certain events and transactions that are discovered after the end of the present financial exercise, but before the publishing of the financial situations.

The principle of the historical or original cost - presupposes that the evaluation of the elements included in the financial situations are accomplished on the basis of the entry value, value that is kept until their departing from the unit, with the exception of certain special operations such as the re-evaluations and adjustments of value accomplished in different moments of the accounting- informational flow. This principle envisages at the same time another principle, especially of a judicial nature, that is the principle of the monetary nominalism. The historical or original cost is the one that was sustained by the company at the entry of an element in the company's national wealth (Pantea, 2003, p.164).

It represents at the same time a basis for other types of evaluations, and in the conditions of an inflationary monetary system it can become unreal. Paragraph 1, article 12 of The French Commerce Code 21 mentions: "at the date of entrance in the company's national wealth the goods purchased with valuable consideration are registered at their acquisition or initial cost, the goods purchased with free title, at their utility value (venal one), the produced goods, at the acquisition cost".

The guideline authorizes the member states to accomplish waivers from the principle of the historical or original cost, as it follows: 
- The evaluation on the basis of the replacement value for the tangible fixed assets of whose utility is limited in time and for stocks;

- The evaluation on the basis of other methods, method that are destined to take into account the inflation;

- A re-evaluation of the tangible fixed assets and the financial ones.

The principle of the separate evaluation of the elements of asset and liability (Chebac, 2009, p. 223) envisages the fact that the establishing of the face amount/ value in the financial situations for a certain item are going to be determine separately, as well for the elements of the accounting balance sheet, as for the ones assignable to the loss and profit account.

This principle functions in a tight correlation with other main principles, according to the recommendations of the Fourth Guideline of the EU, such as follows: the continuity of the activity, the permanence of methods, prudence, the independence of the exercises and the intangibility of the opening balance sheet. Also, the content of this principle from the point of view of the applicability zone must be analysed depending upon the way of utilization of the evaluation bases, in which an important role have the efficiency of the professional reason and the reasonable appreciation of the significance threshold that must present the financial information obtained through the application of this principle.

The principle of the predomination of the economic part upon the juridical one presupposes that the financial situations must reflect the economic reality of the events and transactions, not only their juridical form. The necessity of applying this principle is imposed because the real and concrete applicability ways and modalities of these principles generate an inter-conditioning mutual report between the economic and the juridical reality. The importance of this principle consists in the fact that its acceptance or non-acceptance leads to a different interpretation of the image concept or faithful presentation. The determination of these concepts raises a series of dilemmas, if one takes into account the fact that their interpretation is different within the accounting currents, thus: for the Anglo- Saxons the faithful image represents the supreme principle, while for the continentals this represents the objective of the financial accounting.

From the point of view of the accounting harmonization, this reached its purpose if we refer to the financial situations. If we refer to the 
accounting principles, we cannot say the same thing, the member states adopting in a different way these principles.

The stipulations of the guideline give a special attention to the prudence concept, principle that is put into direct connection with a series of restrictions referring to the benefits distribution. For example:

- The reserve from the re-evaluation and other similar reserves cannot be distributed as long as they do not correspond to an accomplished surplus value;

- Any distribution can be made, as far as the promotion expenses and the research- development ones were not completely amortized or written off, if the member states do not authorize in another way.

Starting from the main objective of the guideline, that of offering a faithful image of the financial situations, there are also stipulated a series of aspects regarding the excessive value reductions, for example:

- The reserve from the re-evaluation must be abolished in the measure in which the affected sums for it are no longer necessary;

- When the causes that motivated the value corrections for the elements of frozen assets are not actual any more, the corrections must not be maintained any more

- The same disposition is also valid in the case of inventories;

- The risk and expenses provisions must not surpass the necessities.

As far as the taxation is concerned and its report with the accounting, there are stipulated the following aspects:

a) The fiscal processing of the reserve from the re-evaluation must be explained either in the balance sheet, either in the annex;

b) If the elements of frozen asset or current asset make the object of some corrections of fiscal nature, their size and cause must be explained in the annexes;

c) Explanations concerning the way in which the result was affected by an items evaluation, according to another evaluation basis than the one of the historical cost

The administrator's report must contain at least a faithful presentation of the development and performance of the activities of the entity and its financial position, together with a description of the main risks and uncertainties with which it confronts. Also, it must contain indications concerning important events that occurred after the date of the balance 
sheet, the predictable evolution of the society and the activities regarding the research - development process.

\section{Conclusion}

If upon the presentation demands of the financial situations the Fourth Guideline is explicit enough, there are still some aspects upon which this does not pronounce, especially concerning the evaluation and recognition of certain elements of the structures of the financial situations. We consider that this is the reason for which the accounting rules in accordance with the European guidelines approved through OMFP $1752 / 2005$ take over as evaluation rules and accounting acknowledgment the stipulations of the general frame of IASB concerning the problems upon which the Fourth Guideline does not pronounce. Referring to this problem and in order to ensure an implementation process corresponding to the rules mentioned, we consider necessary, on a short term, the development of their stipulations with national accounting norms (standards) that should bring under regulation the evaluation and to reflect in accounting certain events and transactions, such as: the leasing operations, the incomes from current activities, the subventions, the conversion differences, the financial instruments. In time, such national accounting norms (standards) can be extinguished also upon some other types of events and transactions.

We mention that such solutions were also adopted by the other countries that recently became member of the European Union.

\section{References}

[1] Barry, J. - Epstein, M. (2007): The Interpretation and Application of International Standards of Accounting and Financial Reporting. New York, Wiley, 2007.

[2] Bernard, C. (2000): Encyclopédie de comptabilité, contrôle de gestion et audit. Paris, Economica, 2000.

[3] Bunea, S. - Garbina, M. (2005): Synthesis, case studies and grill tests concerning applying IFRS/IAS vol. I and II. Bucharest, CECCAR, 2005.

[4] Chebac, N. (2009): Managerial Accounting. Zigotto, Galati, 2009.

[5] Collection of guides (2004): Collection of guides for the Understanding and Applying the International Standards of Accounting (32 volumes). Bucharest, CECCAR, 2004; 
Turtureanu, A.G. - Tureac, C.E.: International and European in the Accounting System of Romania.

[6] EC (1978): Fourth Council Directive 78/660/EEC of 25 July 1978 based on Article 54 (3) (g) of the Treaty on the annual accounts of certain types of companies. [on-line], Luxembourg, European Commission, c1978, [cit. 10 ${ }^{\text {th }}$ June, 2009], $<$ http://eur-lex.europa.eu/LexUriServ/LexUriServ.do?uri=CELEX:31 978L0660:EN:HTML>.

[7] EC (1983): Seventh Council Directive 83/349/EEC of 13 June 1983 based on the Article 54 (3) (g) of the Treaty on consolidated accounts. [on-line], Luxembourg, European Commission, c1978, [cit. $10^{\text {th }}$ June, 2009],

<http://eur-lex.europa.eu/LexUriServ/LexUriServ.do?uri=CELEX:31 983L0349:EN:HTML>.

[8] Feleaga, N. - Malciu, L. (2004): Recognition, Evaluation and Assessment in International Accounting. Bucharest, CECCAR, 2004.

[9] Feleaga, N. - Malciu, L. (2005): Financial Accounting - A European Approach and International. Bucharest, Infomega, 2005.

[10] IASB (2007): International Standards of Financial Reporting. Bucharest, CECCAR, 2007.

[11] Obert, R. (2005): Comptabilite approfondie and revision. Bucharest, Coriges Manuel, 2005.

[12] Pantea, P. (2003): Romanian Accounting Harmonized with EEC Directives. Bucharest, Intelcredo, 2003. 


\title{
International and European in the Accounting System of Romania
}

Anca Gabriela TURTUREANU - Cornelia Elena TUREAC

\begin{abstract}
In order to join the European Union, Romania, as well as the other member countries, must accomplish certain criteria, among which we can mention the adopting of the acquis communautaire. Thus, two Guidelines can be considered the basis of the acquis communautaire for the field of the accounting of the corporations: The Fourth Guideline of the Counsel (78/660/EEC) concerning the yearly accounts of the business corporations and the Seventh Guideline of the Counsel (83/349/EEC) concerning the consolidated accounts of the business corporations. Since these two guidelines does not cover the banking industry and the insurance industry, there were adopted two Guidelines in order to cover the problems that appear in the yearly accounts (financial situations) of these two sectors (The Accounts Guideline of the Banking Industry from 1986 and The Accounts Guideline of the of the Insurance Industry from 1991). These four Guidelines are considered to be the fundamental pillars of the acquis, with relevance.
\end{abstract}

Key words: Financial Reporting; IFRS; Romania; Romanian Accounting Practices.

JEL classification: M41. 